\title{
Oral adenosine 5'-triphosphate supplementation improved hemodynamic and autonomic parameters after exercise in hypertensive women
}

\author{
Marcelo Conrado de Freitas ${ }^{1,2}$, Ana Laura Ricci-Vitor ${ }^{3}$, Renan Valero Freire', Erico Chagas Caperuto ${ }^{4}$, Luiz Carlos Marques Vanderlei ${ }^{3}$, \\ Fábio Santos Lira ${ }^{5}$ Fabrício Eduardo Rossi i,** \\ ${ }^{1}$ Skeletal Muscle Assessment Laboratory (LABSIM), São Paulo State University (UNESP), School of Technology and Sciences, Department of Physical Education, Presidente \\ Prudente, Brazil \\ ²Department of Nutrition, São Paulo Western University-UNOESTE, Presidente Prudente, Brazil \\ ${ }^{3}$ Department of Physiotherapy, São Paulo State University (UNESP), Presidente Prudente, Brazil \\ ${ }^{4}$ University São Judas Tadeu, São Paulo, Brazil \\ ${ }^{5}$ Exercise and Immunometabolism Research Group, Department of Physical Education, São Paulo State University (UNESP), Presidente Prudente, Brazil \\ ${ }^{6}$ Immunometabolism of Skeletal Muscle and Exercise Research Group, Department of Physical Education, Federal University of Piauí (UFPI), Teresina, Brazil
}

The aim of this study was to verify the autonomic modulation and blood pressure after adenosine-5'-triphosphate (ATP) supplementation associated to acute aerobic exercise in hypertensive women. Eleven hypertensive women (age, $61.8 \pm 5.0$ years) completed a randomized, double blind trial: ATP supplement condition (ATP $=400 \mathrm{mg}$ ) or placebo. After 30 min of supplementation or placebo intake, the subjects performed 30 min of aerobic exercise $(70 \%-75 \%$ of maximum heart rate). The autonomic modulation was assessed by heart rate variability during rest and recovery (postexercise until $30 \mathrm{~min}$ of recovery), the square root of the mean squared difference between adjacent RR intervals (RMSSD), standard deviation of successive values (SDNN), low frequency (LF) and high frequency (HF) were measured. The blood pressure (systolic blood pressure [SBP] and diastolic blood pressure, $\mathrm{mmHg}$ ) were recorded at rest, immediately postexercise, post- 10 , post-20, and post -30 min after exercise. For RMSSD, there was statistically significant differ- ence during recovery, with higher RMSSD for ATP compared to placebo (rest $=16.4 \pm 8.5$ vs. placebo $=11.6 \pm 4.0 ; A T P=18.5 \pm 9.7 \mathrm{msec} ; P=0.020$ ). When analyzing the delta (recovery minus rest), the RMSSD (ATP $=2.1 \pm$ $7.2 \mathrm{msec}$ vs. placebo $=-4.7 \pm 7.5 \mathrm{msec} ; P=0.009), \mathrm{LF}(\mathrm{ATP}=-19.8 \pm 122.7$ vs. placebo $\left.=-94.1 \pm 200.2 \mathrm{msec}^{2} ; P=0.02\right)$, and SDNN (ATP $=-2.8 \pm 12.2$ msec vs. placebo $=-10.6 \pm 10.5 \mathrm{msec} ; P=0.010$ ) were higher for ATP than placebo. Furthermore, there was a greater postexercise hypotension at $20 \mathrm{~min}$ for ATP (SBP: ATP $=-13.2 \pm 8.4 \mathrm{mmHg}$ vs. placebo $=-6.1 \pm 9.9 \mathrm{mmHg}$; $P=0.006$ ). Acute ATP supplementation promoted greater postexercise hypotension for systolic blood pressure and induced faster recovery of heart rate variability in hypertensive women.

Keywords: Aerobic exercise, ATP supplementation, Nutrition, Autonomic nervous system, Hypertension

\section{INTRODUCTION}

High blood pressure has been associated with cardiovascular risk and mortality (Heidenreich et al., 2011; Mozaffarian et al., 2015), and this disease is considered a major public health problem, with worldwide prevalence rate around one billion and increasing direct healthcare costs (Kearney et al., 2005; Mills et al.,
2016; Ostchega et al., 2008). Furthermore, previous studies demonstrated that hypertensive subjects have several dysfunctions on the autonomic nervous system (ANS) and vascular tissue (Grassi and Ram, 2016; Kario et al., 1997), generating the increase of blood pressure. On the other hand, regular exercise has been effective in preventing this disease and is strongly recommended for hypertension treatment (Besnier et al., 2017; Corne-
${ }^{*}$ Corresponding author: Fabrício Eduardo Rossi

(iD) https://orcid.org/0000-0002-0594-2529

Department of Physical Education, Federal University of Piauí (UFPI),

"Ministro Petrônio Portella" Campus, 64049-550, Teresina-PI, Brazil

Tel: +86-3215-5525, Fax: +86-3215-55264391, E-mail: rossifabricio@yahoo.com.br

Received: May 13, 2018 / Accepted: July 14, 2018
This is an Open Access article distributed under the terms of the Creative Commons Attribution Non-Commercial License (http://creativecommons.org/licenses/by-nc/4.0/) which permits unrestricted non-commercial use, distribution, and reproduction in any medium, provided the original work is properly cited. 
lissen and Smart, 2013; Cornelissen et al., 2013).

Regarding the ANS, heart rate variability (HRV) is an accepted method to analyze changes on the ANS, which describes the oscillations in the interval between consecutive heart beats and it can provide information about the behavior of sympathetic and parasympathetic components of the ANS (Shaffer and Ginsberg, 2017). There is a relationship between reductions of HRV at rest with ventricular arrhythmias and sudden cardiac death (Pokorný et al., 2011; Vinik et al., 2011; Volders, 2010) as well as increased in morality risk (Kleiger et al., 1987). HRV also can be used to evaluate cardiovascular overload and stress induced by exercise (Borresen and Lambert, 2008; Stanley et al., 2013). In addition, the evaluation of HRV during exercise recovery is essential to determine clinical interventions for individuals with cardiovascular disease, once after exercise occurs reductions in HRV (Cabral-Santos et al., 2016), which is considered a critical period to development of arrhythmias, ischemia, ectopic heart activity and sudden cardiac death in cardiac patients (Kenttä et al., 2012; Lahiri et al., 2012; Thompson et al., 2007).

Previous studies showed that acute aerobic exercise can reduce the blood pressure, a condition denominated postexercise hypotension $(\mathrm{PEH})$, which has an important contribution in controlling high blood pressure (Gomes Anunciação and Doederlein Polito, 2011; Pescatello et al., 2004). Studies demonstrated that during exercise recovery period, the combination of sustained postexercise vasodilatation with reduction in sympathetic nerve activity as well as increasing parasympathetic tone contributes considerably for PEH (Gomes Anunciação and Doederlein Polito, 2011; Halliwill, 2001; Kulics et al., 1999). In this context, nutritional interventions with effects on vasodilatation and autonomic modulation may potentiate fall in arterial blood pressure after exercise.

It has been investigated the influence of oral adenosine-5'-triphosphate (ATP) supplementation on resistance exercise performance, demonstrating ergogenic effects (Freitas et al., 2017; Purpura et al., 2017; Wilson et al., 2013). The great interest of ATP supplementation can be associated with physiological effects of extracellular ATP on skeletal muscle excitability and vascular tissue. During exercise, under conditions of low oxygen availability in the muscle, red blood cells release ATP to bind at purinergic receptor P2Y, increasing the synthesis of vasodilator substances (nitric oxide, prostaglandin, and endothelial-derived hyperpolarization factors), thus maximizing vasodilation and blood flow in the skeletal muscle (Casey and Joyner, 2012; González-Alonso, 2012; Mortensen and Saltin, 2014). Although oral ATP supplementation likely does not increase the bioavailability of extracel- lular ATP (Arts et al., 2012), a study with animals conducted by Kichenin and Seman (2000) found that chronic ATP administration enhanced ATP uptake and synthesis in the erythrocyte, suggesting that ATP supplementation can increase ATP levels in erythrocyte and this may enhance vasodilatation and blood flow.

Regarding the cardiovascular system, it is not clear at the literature about the effects of ATP supplementation. Jäger et al. (2014) demonstrated that ATP supplementation increased blood flow after resistance exercise in animals and humans, and they suggested that the vasodilation effect by extracellular ATP could explain the increased of blood flow. Given that the vasodilatation can reduce blood pressure (Halliwill, 2001; Joyner and Casey, 2015) and ATP supplementation increased blood flow after exercise in humans (Jäger et al., 2014), improvements in PEH in hypertensive patients with ATP supplementation may be plausible. In addition, whether ATP supplementation can influence autonomic recovery after exercise is unknown in the literature.

Thus, the aim of this study was to verify the autonomic modulation and blood pressure after ATP supplementation associated to acute aerobic exercise in hypertensive women. We hypothesized that a single dose of ATP supplementation could potentiate PEH and improved autonomic parameters recovery in hypertensive women.

\section{MATERIALS AND METHODS}

\section{Experimental design}

This study used a randomized, double-blind design. Participants completed two experimental trials in the laboratory, which was separated by seven days. To ensure chronobiological control, all experimental trials were performed at the same period of the day (in the morning). The first visit included anthropometric measurements. During the following two visits, each participant consumed either the placebo or ATP supplementation randomly, and then completed $30 \mathrm{~min}$ of aerobic exercise. The blood pressure and HRV were evaluated. The experimental design is presented in Fig. 1.

\section{Subjects}

The study included eleven hypertensive women who were submitted to two experimental trials, separated by seven days. To be included in the study the participants had to meet the following criteria: (a) have medical diagnosis of hypertension and permission to participate in the training; (b) absence of health problems that could prevent the completion of the assessments and exercise interventions (i.e., absence of limbs, hurting joints); (c) to not use 


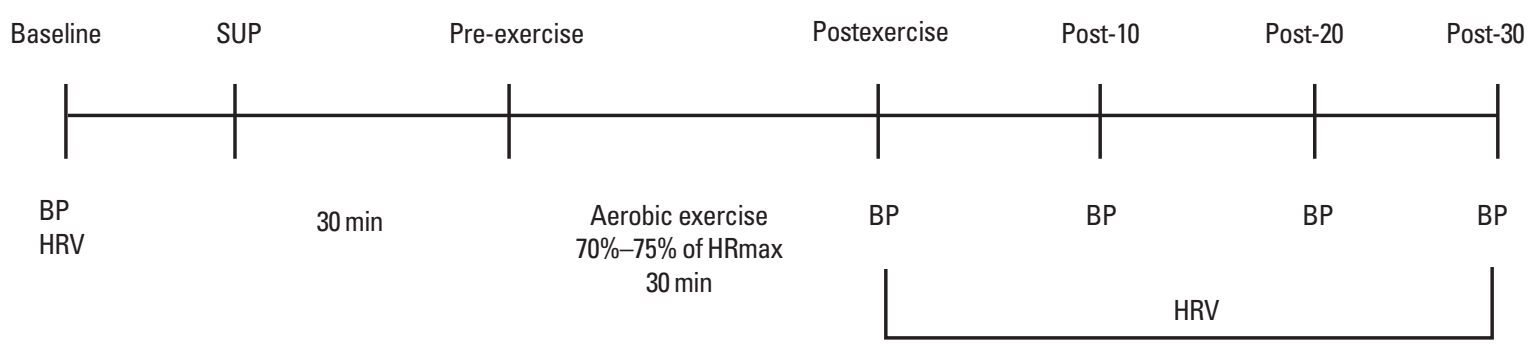

Fig. 1. Experimental design. BP, blood pressure; HRV, heart rate variability; SUP, $400 \mathrm{mg}$ of ATP or placebo; ATP, adenosine-5'-triphosphate; HRmax, maximum heart rate.

supplementation during the study or other substances (vitamins). The participants were instructed to not take any medicine before each experimental trial. After being informed of the risks and benefits involved in the study, the participants signed a consent form. The project was approved by the Ethics Research Group of the University of São Judas, São Paulo-SP, Brazil (protocol number: 66523717.2.0000.0089) and the research was conducted according to the 2008 Revision of the Declaration of Helsinki.

\section{Procedures}

\section{Anthropometric measurements}

Anthropometry was composed of body weight and height measurements. Height was measured with a fixed-stadiometer, Sanny brand, with an accuracy of $0.1 \mathrm{~cm}$ and a length of $2.20 \mathrm{~m}$. Body weight was measured using an electronic scale (Sanny brand, São Paulo, Brazil), with a precision of $0.1 \mathrm{~kg}$. Subsequently, the body mass index was calculated $\left(\mathrm{BMI}=\right.$ weight $[\mathrm{kg}] /$ height $\left.^{2}[\mathrm{~m}]\right)$.

\section{Supplementation protocol and dietary intake}

Each participant ingested randomly either: $400 \mathrm{mg}$ of oral ATP supplementation (ProMera Health LLC, Norwell, MA, USA $200 \mathrm{~mL}$ : 400-mg adenosine-5'-triphosphate disodium) or placebo (Clight Juice, Kraft Foods, São Paulo, Brazil - 200 mL: energy 21 $\mathrm{kj}, 5 \mathrm{kcal}$, sodium $4.7 \mathrm{mg}$ ). Supplementation or placebo was ingested $30 \mathrm{~min}$ before exercise supplied in identical bottles. To ensure double-blind design, we chose this specific juice (Clight) as placebo due to flavor similarity with ATP supplement (Freitas et al., 2017).

All participants were required to answer a food questionnaire reporting their dietary intake (breakfast) before the exercise protocol. To ensure that dietary intake was similar between the trials, participants were instructed to replicate the first trial's dietary intake in the subsequent trial. Data were analyzed by the same nutritionist using NutWin software ver. 1.5 (a program for assisting nutrition by the Federal University of São Paulo, Brazil, 2002) and total kilocalories intake $(\mathrm{kcal})$ and macronutrient in grams (carbohydrates, lipids, and protein) were identified. During the study, all participants were instructed not to use any other supplementation or ergogenic substances (i.e., caffeine), as well as make changes to their regular diet.

\section{Blood pressure and autonomic modulation measurements}

Blood pressure was recorded at rest, immediately post-exercise, post-10, post-20 and post-30 min after exercise. The systolic and diastolic blood pressure were measurement using automatic blood pressure monitor (Omron Healthcare brand Inc., Intellisense, Model HEM 742 INT, Bannockburn, IL, USA) previously validated (Coleman et al., 2005).

The autonomic modulation was recorded at rest for $30 \mathrm{~min}$, and during recovery (postexercise until $30 \mathrm{~min}$ after exercise). It was measured through HRV and expressed by time and frequency domains. Subjects were instructed to remain in silence, awake, at rest, breathing spontaneously in the supine position. After the procedures had been explained, an elastic strap was placed at the height of the xiphoid process of the subject and a heart rate (HR) receptor on the wrist (Polar Electro, model S810i or RS800, Kempele, Finland). This equipment has been previously validated to record beat-to-beat HR and HRV analysis (Vanderlei et al., 2008), and the same procedures were conducted on both days of the test.

The temporal recording of the interval between consecutive cardiac beats (RR) was submitted to digital filtering complemented by manual filtering using the Polar software. Only sets with more than $95 \%$ sino-atrial node beats were included in this study. After this, intervals of 5 min were analyzed in Kubios software (Biosignal Analysis and Medical Image Group, Department of Physics, University of Kuopio, Kuopio, Finland) (Vanderlei et al., 2009). For time domain, the analysis included the square root of the mean squared difference between adjacent $R R$ intervals (RMSSD), standard deviation of all normal RR intervals (SDNN). 
For frequency domain, the analysis included spectral components of low frequency (LF: frequency between 0.04 and $0.15 \mathrm{~Hz}$ ) and high frequency (HF: frequency between 0.15 to $0.4 \mathrm{~Hz}$ ) expressed in normalized units. Spectral analysis was calculated using Fast Fourier Transform (Vanderlei et al., 2009).

\section{Exercise protocol}

Before the exercise protocol, subjects completed a warm-up, which consisted of 5 min of walking. After this, the participants performed 30 min of moderate to vigorous aerobic exercise on a track according to the recommendation of the American College of Sports Medicine (Nelson et al., 2007). Participants were instructed to walk or run maintaining HR between $70 \%-75 \%$ of maximum HR. The HR was recorded using a digital stopwatch (model S810i; Polar Electro, Kempele, Finland). After exercise, all subjects laid down for $30 \mathrm{~min}$ to perform the hemodynamic and autonomic modulation procedures. All training sessions were conducted under the supervision of physical education professionals and students who had been previously familiarized with the training program.

\section{Statistical analysis}

The average of 30 min during recovery was calculated for HRV and blood pressure. A repeated measures analysis of variance with Bonferroni adjustment for multiple comparisons was used to compare HRV mean and blood pressure mean according to three different conditions (rest, ATP, and placebo). For all measured variables, the estimated sphericity was verified according to Mauchly's W test, and the Greenhouse-Geisser correction was

Table 1. General characteristics and dietary intake of the sample $(n=11)$

\begin{tabular}{lc}
\hline Characteristic & Value \\
\hline Age $(\mathrm{y})$ & $61.8 \pm 5.0$ \\
Height $(\mathrm{cm})$ & $161.8 \pm 0.05$ \\
Weight $(\mathrm{kg})$ & $67.7 \pm 10.3$ \\
Body mass index $\left(\mathrm{kg} / \mathrm{m}^{2}\right)$ & $26.0 \pm 2.9$ \\
Dietary intake pre-exercise & \\
Diet carbohydrate (g) & $40.4 \pm 28.5$ \\
Diet protein (g) & $7.4 \pm 4.5$ \\
Diet lipids (g) & $8.1 \pm 7.5$ \\
Total intake (kcal) & $257 \pm 170$ \\
Exercise intensity $(\% H R m a x)$ & \\
Placebo & $73.1 \pm 2.0$ \\
ATP & $73.5 \pm 3.2$ \\
\hline
\end{tabular}

Values are presented as mean \pm standard deviation. \%HRmax, percentage of maximum heart rate; ATP, adenosine-5'-triphosphate. used when necessary. Furthermore, delta was calculated for HRV ( $\Delta=$ recovery minus rest) and blood pressure ( $\Delta=$ post- $20 \mathrm{~min}$ minus rest). The comparison of the delta was performed using the Student $t$-test for dependent samples. Statistical significance was set at $P<0.05$. The effect size (eta-squared $=\eta^{2}$ ) test was calculated for time. Data were analyzed using Stata 10 (StataCorp LP., College Station, TX, USA).

\section{RESULTS}

Table 1 presents values of mean and standard deviation for age, body weight, height, dietary intake pre-exercise and exercise intensity during two experimental trials. For exercise intensity, no significant difference was observed between trials.

Table 2 shows the differences in HR and autonomic modulation according to temporal and frequency domain between placebo and ATP condition. For HR (bpm) there was a main effect of time $\left(F=19.249, P<0.001, \eta^{2}=0.68\right)$ with higher HR for placebo and ATP in relation to rest, however, no significant difference were observed between trials.

For RMSSD, there was statistically significant difference during recovery $\left(F=4.917, P=0.020, \eta^{2}=0.35\right)$, with significant higher RMSSD for ATP compared to placebo $(P=0.027)$. When analyzed SDNN, there was no statistically significant difference $(F=2.414$, $\left.P=0.118, \eta^{2}=0.21\right)$, however, Bonferroni post hoc demonstrated significant greater SNDD in the ATP conditions compared to placebo $(P=0.041)$.

Regarding frequency domain (LFmsec ${ }^{2}$ and HFmsec ${ }^{2}$ ), there were no significant difference during recovery $(P>0.05)$. For LFnu, HFnu, and LF/HF ratio, there were no statistically signifi-

Table 2. Comparison on heart rate and heart rate variability

\begin{tabular}{lccc}
\hline Variable & Rest & Placebo recovery & ATP recovery \\
\hline Heart rate (bpm) & $69.8 \pm 9.3$ & $83.3 \pm 4.5^{\text {a) }}$ & $79.5 \pm 9.9^{\text {a) }}$ \\
SDNN (msec) & $30.5 \pm 13.1$ & $27.5 \pm 8.2$ & $33.6 \pm 12.9$ \\
RMSSD (msec) & $16.4 \pm 8.5$ & $11.6 \pm 4.0$ & $18.5 \pm 9.7^{\text {b) }}$ \\
LF $\left(\mathrm{msec}^{2}\right)$ & $249.8 \pm 231.3$ & $155.6 \pm 119.0$ & $229.9 \pm 163.6$ \\
HF $\left(\mathrm{msec}^{2}\right)$ & $104.1 \pm 84.9$ & $48.83 \pm 30.1$ & $109.2 \pm 106.4$ \\
LF/HF ratio & $2.32 \pm 1.0$ & $3.35 \pm 1.5$ & $3.83 \pm 2.3$ \\
LF $($ nu) & $60.43 \pm 22.1$ & $71.9 \pm 9.2$ & $68.33 \pm 9.4$ \\
HF (nu) & $33.52 \pm 11.4$ & $28.04 \pm 9.3$ & $31.31 \pm 9.3$ \\
\hline
\end{tabular}

Values are presented as mean \pm standard deviation. ATP, adenosine-5'-triphosphate; SDNN, standard deviation of all normal RR intervals; RMSSD, square root of the mean squared difference between adjacent RR intervals; LF, low frequency; HF, high frequency.

a)Statistically significantly differences from rest. ${ }^{b}$ Statistically significantly differences between ATP and placebo conditions. 

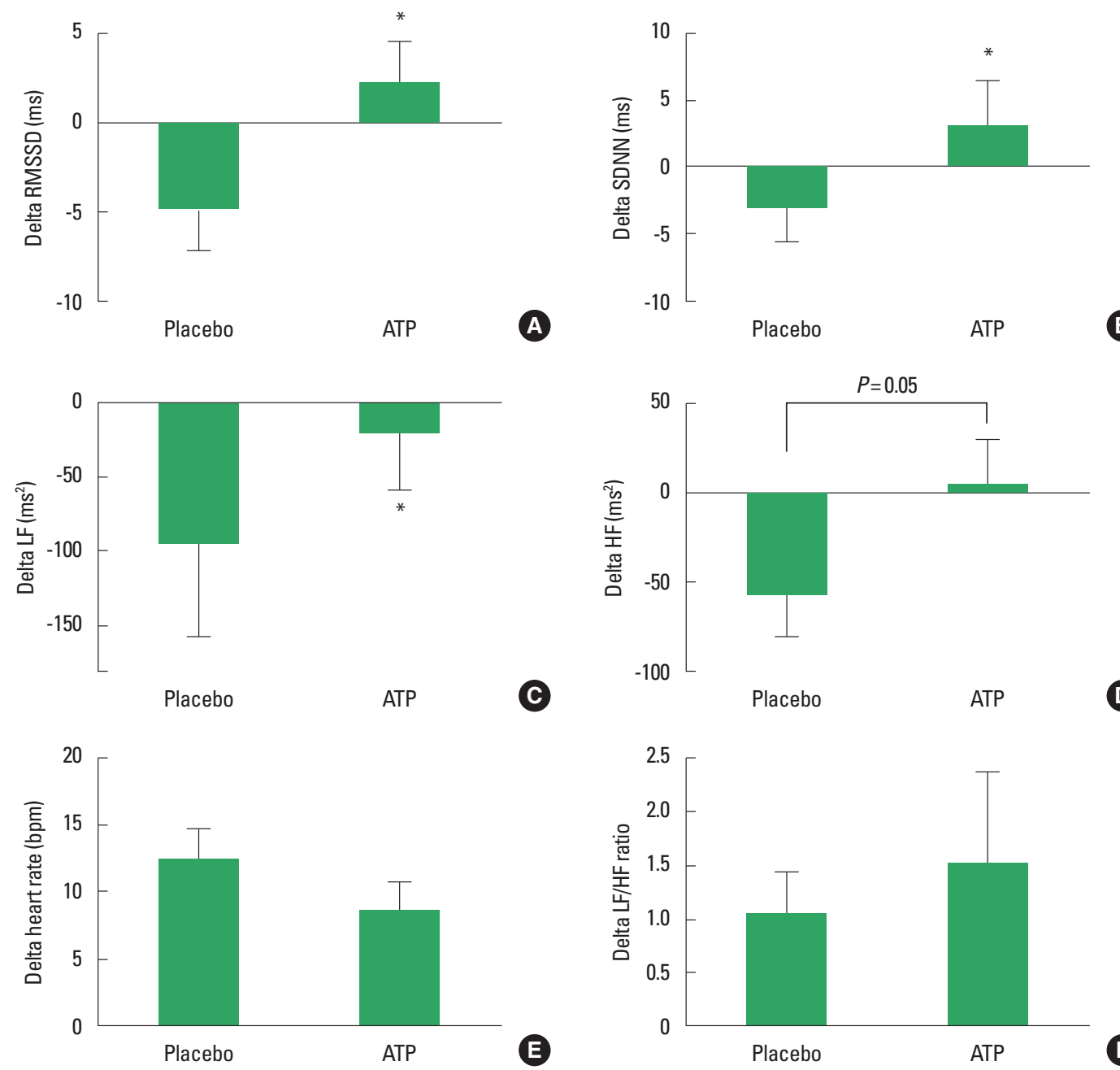

Fig. 2. Comparison on delta heart rate and heart rate variability. (A) Delta (recovery minus rest) of the square root of the mean squared difference between adjacent RR intervals (RMSSD, ms). (B) Delta of the standard deviation of all normal RR intervals (SDNN, ms). (C) Delta of the low frequency (LF, ms ${ }^{2}$ ). (D) Delta of the high frequency $\left(\mathrm{HF}, \mathrm{ms}^{2}\right.$ ). (E) Delta of the heart rate. (F) Delta of the LF/HF ratio. ATP, adenosine-5'-triphosphate. *Statistically significantly differences between ATP and placebo conditions.

cant difference during recovery between conditions $(P>0.05)$.

Fig. 2 shows the delta ( $\Delta=$ recovery minus rest $)$ in $\mathrm{HR}$ and autonomic modulation between placebo and ATP condition. For RMSSD, there was a significant greater values for ATP compared to placebo $(\mathrm{ATP}=2.2 \pm 7.2 \mathrm{msec}$ vs. placebo $=-4.7 \pm 7.6 \mathrm{msec}$; $P=0.009)$. In addition, delta analysis showed significant higher SDNN for ATP $($ ATP $=3.1 \pm 10.8$ msec vs. placebo $=-2.9 \pm 8.5$ msec, $P=0.014)$. LFmsec $^{2}$ was statistically lower for placebo in relation to ATP (ATP $=-19.9 \pm 122.7 \mathrm{msec}^{2}$ vs. placebo $=-94.2 \pm$ $200.3 \mathrm{msec}^{2}, P=0.028$ ) and there was a trend to a significant difference in the HFmsec ${ }^{2}\left(\mathrm{ATP}=5.1 \pm 77.6 \mathrm{msec}^{2}\right.$ vs. Placebo $=$ $\left.-55.3 \pm 80.5 \mathrm{msec}^{2}, P=0.05\right)$.

Fig. 3 presents the differences in blood pressure in placebo and
ATP condition.

Regarding SBP $(\mathrm{mmHg})$, there was a main effect of time $\left(F=12.649, P<0.001, \eta^{2}=0.55\right)$, but no difference between conditions and interaction were verified $(P>0.05)$. However, when analyzed the delta ( $\Delta=$ post-20 min minus rest), there was a significant lower SBP for ATP compared to placebo (ATP = $-13.18 \pm 8.3 \mathrm{~mm} / \mathrm{Hg}$ vs. placebo $=-6.1 \pm 9.9 \mathrm{~mm} / \mathrm{Hg}, P=0.006)$. For DBP $(\mathrm{mmHg})$, there was no main effect of time, interaction and conditions $(P>0.05)$.

\section{DISCUSSION}

To our knowledge, this was the first study to verify the effects 

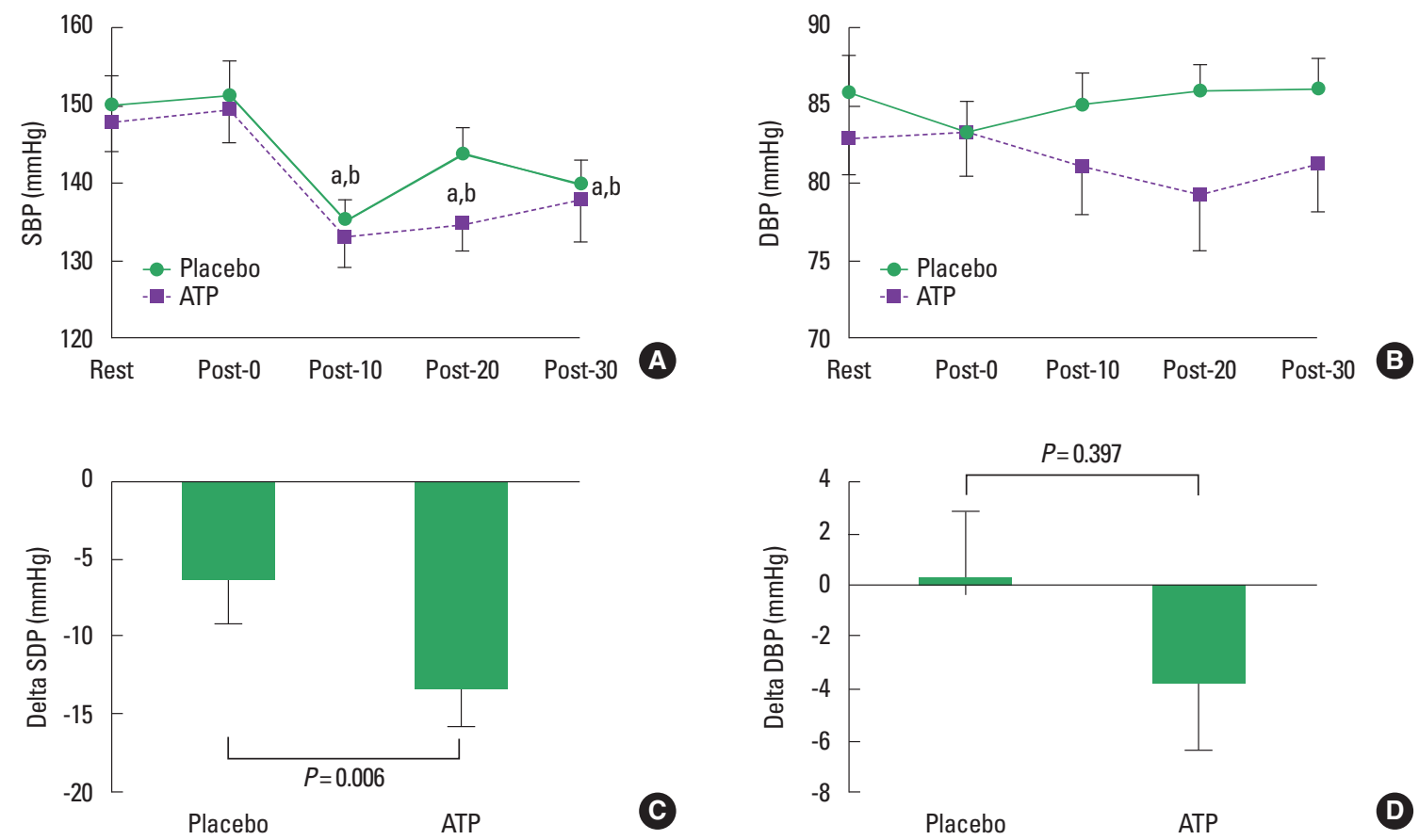

C

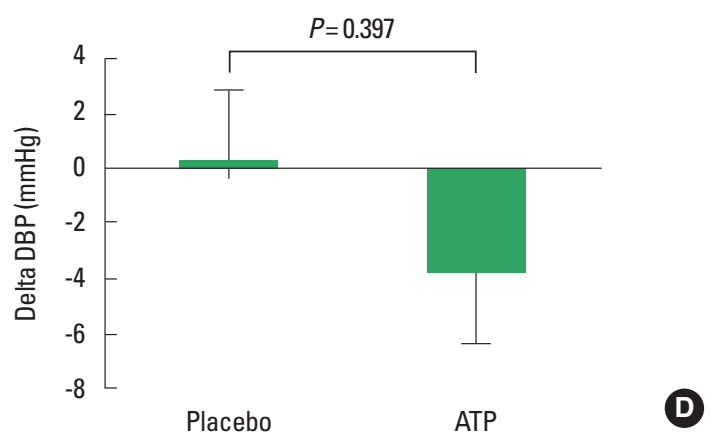

Fig. 3. Comparison on systolic and diastolic blood pressure for ATP and Placebo conditions. (A) Systolic blood pressure across time (SBP, mmHg). (B) Diastolic blood pressure across time (DBP, mmHg). (C) Delta of systolic blood pressure (Post-20 min of recovery minus rest). (D) Absolute variation on diastolic blood pressure (Post-20 min of recovery minus rest). $a$, main effect of time with difference between rest; $b$, main effect of time with difference between 5 min. ATP, adenosine-5'-triphosphate.

of ATP supplementation on HRV and blood pressure after acute aerobic exercise in hypertensive women. The major finding of the present study were that a single dose of ATP supplementation increased parasympathetic modulation after exercise, and promoted a higher magnitude of the PEH with lower SBP compared to placebo after $20 \mathrm{~min}$ of aerobic exercise in hypertensive women.

The investigation about the influence of ATP supplementation on exercise performance is widely explored in the literature, demonstrating ergogenic effects (Freitas et al., 2017; Purpura et al., 2017; Wilson et al., 2013). Recently, our group investigated the acute influences of ATP supplementation on performance during resistance exercise ( 4 sets until muscular failure with $80 \%$ of one-repetition maximum in squat exercise) and physiological response in trained men. The results showed higher performance, oxygen consumption and energy expenditure with ATP supplementation compared with placebo (Freitas et al., 2017), however, the effect of acute ATP supplementation on blood pressure and autonomic modulation after exercise is unknown at the literature.

According our data, we observed that ATP supplementation potentiated the parasympathetic recovery after exercise, with higher RMSSD and delta LF values compared to placebo, demonstrating that ATP supplementation could contribute to autonom- ic modulation balance after exercise. In addition, changes in SDNN (delta) were higher for ATP in relation to placebo, which maybe occurred due to higher parasympathetic modulation for ATP condition while decreased for placebo, once both sympathetic and parasympathetic activity contribute to SDNN (Shaffer and Ginsberg, 2017; Vanderlei et al., 2009).

There is a relationship between reductions of rest parasympathetic modulation with ventricular arrhythmias and sudden cardiac death (Pokorný et al., 2011; Vinik et al., 2011; Volders, 2010). In addition, lower SDNN value is associated with a higher 5.3 times risk of mortality after acute myocardial infarction (Kleiger et al., 1987) as well as lower RMSSD and SDNN are associated with higher cardiovascular disease and mortality risk (Thayer et al., 2010). Considering that, after exercise there is an increased risk of adverse effects in cardiac patients, for example as ischemia and ectopic heart activity (Thompson et al., 2007) and the parasympathetic modulation is lower (Cabral-Santos et al., 2016), our results may be a great clinical implication, once ATP supplementation could be used to recovery faster parasympathetic modulation after exercise, decreasing the risk of a cardiovascular event in cardiac patients following exercise.

Regarding blood pressure, both protocols induced PEH in the 
present study; however, ATP supplementation potentiated the magnitude of $\mathrm{PEH}$, once our findings showed that changes in SBP (delta) was lower at $20 \mathrm{~min}$ after exercise in ATP condition than placebo. These findings have an important clinical repercussion, once the magnitude and duration of $\mathrm{PEH}$ are important for blood pressure control in hypertensive individuals (Gomes Anunciação and Doederlein Polito, 2011). We believe that the increase in parasympathetic modulation after exercise by ATP supplementation influenced blood pressure results, once PEH is mediated in part by the ANS (Gomes Anunciação and Doederlein Polito, 2011; Halliwill, 2001; Kulics et al., 1999).

Another possible mechanism by ATP supplementation maybe influence blood pressure response is through the physiological effects of extracellular ATP on vascular tissue. During muscle contraction blood erythrocytes releases ATP which binds to the P2Y receptor in the endothelial tissue, inducing the production of substances with vasodilatation effects (endothelium-derived hyperpolarizing factor, prostacyclin, and nitric oxide), and thus relaxing the smooth muscle of the vasculature (González-Alonso, 2012). It has been reported that the maintenance of vasodilatation after exercise has a great impact on PEH (Halliwill, 2001). In this sense, Jäger et al. (2014) showed that ATP supplementation potentiated the blood flow after resistance exercise in rats and humans, suggesting that vasodilatory effects of extracellular ATP mediated these responses. Thus, we hypothesize that the reduction in SBP after exercise can be associated with vasodilatation induced by ATP supplementation. Supporting this, Wang et al. (2015) demonstrated that vascular introduction of P2Y (extracellular ATP receptor) agonist induced vasodilatation in a nitric oxide dependent-manner and reduced blood pressure in mice, suggesting that activation of purinergic signaling in endothelium may decrease the blood pressure.

From a practical point of view, the present study suggests that ATP supplementation can be used as a nutritional strategy to induced faster recovery of HRV after exercise by increasing parasympathetic modulation in hypertensive women. Thus, the results of this study may be applied by professionals to reduce the risk of a cardiovascular event in cardiac patients following exercise as well as may be used to potentiate the reduction of systolic blood pressure after exercise in individuals with hypertension. Despite the importance of our data, some limitations need to be considered: such as a small sample size and indirect HRV measurement as well as the HRV recovery was analyzed only during $30 \mathrm{~min}$ after exercise. Furthermore, the form and dose of ATP supplementation in the present study were well tolerated, and none of the partici- pants reported adverse effects. Thus, we suggests future studies analyzing the influence of chronic ATP supplementation associated or no with exercise on blood pressure and HRV in cardiac patients.

In conclusion, a single dose of ATP supplementation reduced systolic blood pressure after aerobic exercise. In addition, our results showed that ATP supplementation induced faster recovery of HRV, increasing the parasympathetic modulation after a bout of moderate aerobic exercise in hypertensive women.

\section{CONFLICT OF INTEREST}

No potential conflict of interest relevant to this article was reported.

\section{REFERENCES}

Arts IC, Coolen EJ, Bours MJ, Huyghebaert N, Stuart MA, Bast A, Dagnelie PC. Adenosine 5'-triphosphate (ATP) supplements are not orally bioavailable: a randomized, placebo-controlled cross-over trial in healthy humans. J Int Soc Sports Nutr 2012;9:16.

Besnier F, Labrunée M, Pathak A, Pavy-Le Traon A, Galès C, Sénard JM, Guiraud T. Exercise training-induced modification in autonomic nervous system: An update for cardiac patients. Ann Phys Rehabil Med 2017;60:27-35.

Borresen J, Lambert MI. Autonomic control of heart rate during and after exercise: measurements and implications for monitoring training status. Sports Med 2008;38:633-646.

Cabral-Santos C, Giacon TR, Campos EZ, Gerosa-Neto J, Rodrigues B, Vanderlei LC, Lira FS. Impact of high-intensity intermittent and moderate-intensity continuous exercise on autonomic modulation in young men. Int J Sports Med 2016;37:431-435.

Casey DP, Joyner MJ. Compensatory vasodilatation during hypoxic exercise: mechanisms responsible for matching oxygen supply to demand. J Physiol 2012;590:6321-6326.

Coleman A, Freeman P, Steel S, Shennan A. Validation of the Omron MX3 Plus oscillometric blood pressure monitoring device according to the European Society of Hypertension international protocol. Blood Press Monit 2005;10:165-168.

Cornelissen VA, Buys R, Smart NA. Endurance exercise beneficially affects ambulatory blood pressure: a systematic review and meta-analysis. J Hypertens 2013;31:639-648.

Cornelissen VA, Smart NA. Exercise training for blood pressure: a systematic review and meta-analysis. J Am Heart Assoc 2013;2:e004473.

Freitas MC, Cholewa JM, Gerosa-Neto J, Gonçalves DC, Caperuto EC, 
Lira FS, Rossi FE. A single dose of oral atp supplementation improves performance and physiological response during lower body resistance exercise in recreational resistance trained males. J Strength Cond Res 2017 Oct 16 [Epub]. https://doi.org/10.1519/JSC.0000000000002198.

Gomes Anunciação P, Doederlein Polito M. A review on post-exercise hypotension in hypertensive individuals. Arq Bras Cardiol 2011;96: e100-109.

González-Alonso J. ATP as a mediator of erythrocyte-dependent regulation of skeletal muscle blood flow and oxygen delivery in humans. J Physiol 2012;590:5001-5013.

Grassi G, Ram VS. Evidence for a critical role of the sympathetic nervous system in hypertension. J Am Soc Hypertens 2016;10:457-466.

Halliwill JR. Mechanisms and clinical implications of post-exercise hypotension in humans. Exerc Sport Sci Rev 2001;29:65-70.

Heidenreich PA, Trogdon JG, Khavjou OA, Butler J, Dracup K, Ezekowitz MD, Finkelstein EA, Hong Y, Johnston SC, Khera A, Lloyd-Jones DM, Nelson SA, Nichol G, Orenstein D, Wilson PW, Woo YJ; American Heart Association Advocacy Coordinating Committee; Stroke Council; Council on Cardiovascular Radiology and Intervention; Council on Clinical Cardiology; Council on Epidemiology and Prevention; Council on Arteriosclerosis; Thrombosis and Vascular Biology; Council on Cardiopulmonary; Critical Care; Perioperative and Resuscitation; Council on Cardiovascular Nursing; Council on the Kidney in Cardiovascular Disease; Council on Cardiovascular Surgery and Anesthesia, and Interdisciplinary Council on Quality of Care and Outcomes Research. Forecasting the future of cardiovascular disease in the United States: a policy statement from the American Heart Association. Circulation 2011;123:933-944.

Jäger R, Roberts MD, Lowery RP, Joy JM, Cruthirds CL, Lockwood CM, Rathmacher JA, Purpura M, Wilson JM. Oral adenosine-5'-triphosphate (ATP) administration increases blood flow following exercise in animals and humans. J Int Soc Sports Nutr 2014;11:28.

Joyner MJ, Casey DP. Regulation of increased blood flow (hyperemia) to muscles during exercise: a hierarchy of competing physiological needs. Physiol Rev 2015;95:549-601.

Kario K, Motai K, Mitsuhashi T, Suzuki T, Nakagawa Y, Ikeda U, Matsuo T, Nakayama T, Shimada K. Autonomic nervous system dysfunction in elderly hypertensive patients with abnormal diurnal blood pressure variation: relation to silent cerebrovascular disease. Hypertension 1997; 30:1504-1510

Kearney PM, Whelton M, Reynolds K, Muntner P, Whelton PK, He J. Global burden of hypertension: analysis of worldwide data. Lancet $2005: 365: 217-223$

Kenttä T, Viik J, Karsikas M, Seppänen T, Nieminen T, Lehtimäki T, Nikus K, Lehtinen R, Kähönen M, Huikuri HV. Postexercise recovery of the spatial QRS/T angle as a predictor of sudden cardiac death. Heart Rhythm 2012;9:1083-1089.

Kichenin K, Seman M. Chronic oral administration of ATP modulates nucleoside transport and purine metabolism in rats. J Pharmacol Exp Ther 2000;294:126-133.

Kleiger RE, Miller JP, Bigger JT Jr, Moss AJ. Decreased heart rate variability and its association with increased mortality after acute myocardial infarction. Am J Cardiol 1987;59:256-262.

Kulics JM, Collins HL, DiCarlo SE. Postexercise hypotension is mediated by reductions in sympathetic nerve activity. Am J Physiol 1999;276(1 Pt 2):H27-32.

Lahiri MK, Chicos A, Bergner D, Ng J, Banthia S, Wang NC, Subačius H, Kadish AH, Goldberger JJ. Recovery of heart rate variability and ventricular repolarization indices following exercise. Ann Noninvasive Electrocardiol 2012;17:349-360.

Mills KT, Bundy JD, Kelly TN, Reed JE, Kearney PM, Reynolds K, Chen J, He J. Global disparities of hypertension prevalence and control: a systematic analysis of population-based studies from 90 countries. Circulation 2016;134:441-450.

Mortensen SP, Saltin B. Regulation of the skeletal muscle blood flow in humans. Exp Physiol 2014;99:1552-1558.

Mozaffarian D, Benjamin EJ, Go AS, Arnett DK, Blaha MJ, Cushman M, de Ferranti S, Després JP, Fullerton HJ, Howard VJ, Huffman MD, Judd SE, Kissela BM, Lackland DT, Lichtman JH, Lisabeth LD, Liu S, Mackey RH, Matchar DB, McGuire DK, Mohler ER 3rd, Moy CS, Muntner P, Mussolino ME, Nasir K, Neumar RW, Nichol G, Palaniappan L, Pandey DK, Reeves MJ, Rodriguez CJ, Sorlie PD, Stein J, Towfighi A, Turan TN, Virani SS, Willey JZ, Woo D, Yeh RW, Turner MB; American Heart Association Statistics Committee and Stroke Statistics Subcommittee. Heart disease and stroke statistics--2015 update: a report from the American Heart Association. Circulation 2015;131:e29322.

Nelson ME, Rejeski WJ, Blair SN, Duncan PW, Judge JO, King AC, Macera CA, Castaneda-Sceppa C. Physical activity and public health in older adults: recommendation from the American College of Sports Medicine and the American Heart Association. Med Sci Sports Exerc 2007;39:1435-1445.

Ostchega Y, Yoon SS, Hughes J, Louis T. Hypertension awareness, treatment, and control--continued disparities in adults: United States, 2005-2006. NCHS Data Brief 2008;(3):1-8.

Pescatello LS, Franklin BA, Fagard R, Farquhar WB, Kelley GA, Ray CA; American College of Sports Medicine. American College of Sports Medicine position stand. Exercise and hypertension. Med Sci Sports Exerc 2004;36:533-553.

Pokorný J, Staněk V, Vrána M. Sudden cardiac death thirty years ago and 
at present. The role of autonomic disturbances in acute myocardial infarction revisited. Physiol Res 2011;60:715-728.

Purpura M, Rathmacher JA, Sharp MH, Lowery RP, Shields KA, Partl JM, Wilson JM, Jäger R. Oral adenosine-5' -triphosphate (ATP) administration increases postexercise ATP levels, muscle excitability, and athletic performance following a repeated sprint bout. J Am Coll Nutr 2017;36: 177-183.

Shaffer F, Ginsberg JP. An overview of heart rate variability metrics and norms. Front Public Health 2017;5:258.

Stanley J, Peake JM, Buchheit M. Cardiac parasympathetic reactivation following exercise: implications for training prescription. Sports Med 2013;43:1259-1277.

Thayer JF, Yamamoto SS, Brosschot JF. The relationship of autonomic imbalance, heart rate variability and cardiovascular disease risk factors. Int J Cardiol 2010;141:122-131.

Thompson PD, Franklin BA, Balady GJ, Blair SN, Corrado D, Estes NA 3rd, Fulton JE, Gordon NF, Haskell WL, Link MS, Maron BJ, Mittleman MA, Pelliccia A, Wenger NK, Willich SN, Costa F; American Heart Association Council on Nutrition, Physical Activity, and Metabolism; American Heart Association Council on Clinical Cardiology; American College of Sports Medicine. Exercise and acute cardiovascular events placing the risks into perspective: a scientific statement from the American Heart Association Council on Nutrition, Physical
Activity, and Metabolism and the Council on Clinical Cardiology. Circulation 2007;115:2358-2368.

Vanderlei LC, Pastre CM, Hoshi RA, Carvalho TD, Godoy MF. Basic notions of heart rate variability and its clinical applicability. Rev Bras Cir Cardiovasc 2009;24:205-217.

Vanderlei LC, Silva RA, Pastre CM, Azevedo FM, Godoy MF. Comparison of the Polar S810i monitor and the ECG for the analysis of heart rate variability in the time and frequency domains. Braz J Med Biol Res 2008;41:854-859.

Vinik AI, Maser RE, Ziegler D. Autonomic imbalance: prophet of doom or scope for hope? Diabet Med 2011;28:643-651.

Volders PG. Novel insights into the role of the sympathetic nervous system in cardiac arrhythmogenesis. Heart Rhythm 2010;7:1900-1906.

Wang S, Iring A, Strilic B, Albarrán Juárez J, Kaur H, Troidl K, Tonack S, Burbiel JC, Müller CE, Fleming I, Lundberg JO, Wettschureck N, Offermanns S. P2 $\mathrm{Y}_{2}$ and Gq/G11 control blood pressure by mediating endothelial mechanotransduction. J Clin Invest 2015;125:3077-3086.

Wilson JM, Joy JM, Lowery RP, Roberts MD, Lockwood CM, Manninen AH, Fuller JC, De Souza EO, Baier SM, Wilson SM, Rathmacher JA. Effects of oral adenosine-5'-triphosphate supplementation on athletic performance, skeletal muscle hypertrophy and recovery in resistancetrained men. Nutr Metab (Lond) 2013;10:57. 